\title{
SIGILO NO FIM DA CADEIA DE RECICLAGEM: A RECICLAGEM DE RESÍDUOS PLÁSTICOS EM SURABAYA, INDONÉSIA
}

\author{
Freek Colombijn ${ }^{1}$
}

\section{Introdução ${ }^{2}$}

Foi uma longa viagem de táxi até os arredores da cidade de Surabaya (Indonésia) para encontrar a fábrica que, de acordo com informações da internet, produzia plásticos a partir de resíduos reciclados. Em vão, eu havia tentado, sem sucesso, contatar os gestores ou proprietários com antecedência e, então, resolvi fazer uma visita surpresa. Essa fábrica ficava no fim de uma estrada lateral, rodeada por um muro alto. Nenhuma atividade era perceptível dentro ou à volta do muro. Quando bati no portão de ferro, abriu-se uma pequena escotilha no portão e apareceu a cara de um guarda. Com uma risadinha no rosto, o taxista, que tinha estacionado o seu veículo à sombra, observou a minha tentativa de falar com uma parede. Não importava o argumento que eu inventasse, nada persuadia o porteiro a me deixar entrar. Desisti, depois de ele ter consultado outras pessoas superiores, pois ele sequer me permitiu vislumbrar o edifício a partir do portão. "Sekarang mau ke mana, Pak?" (Para onde vamos a partir daqui, senhor?), perguntou-me, na língua local, o taxista, lutando para manter seu rosto sem expressão.

Após a abertura clássica do artigo de Clifford Geertz, 'The Balinese cockfight', os antropólogos gostam de começar os seus textos com uma história ou anedota de campo que, entre outras coisas, mostra a sua relação com os seus temas de investigação. Era eu tão incompetente no trabalho de campo? Ao refletir sobre minha pesquisa, enquanto o taxista me levava para o meu próximo destino, ocorreu-me que a invisibilidade das fábricas formava um padrão, e esta fábrica, em particular, era apenas um caso ex-

1 Vrije Universieit, Holanda. Email : f.colombijn@vu.nl

ORCID id: https://orcid.org/0000-0002-4815-8590

2 Uma versão deste artigo foi originalmente publicada em abril de 2020, na revista World Wide Waste, Journal of Interdisciplinary Studies, disponível no link https://www.worldwidewastejournal.com/articles/10.5334/wwwj.43/

DOI: http://doi.org/10.5334/wwwj.43

A tradução deste trabalho foi realizada com o apoio da Coordenação de Aperfeiçoamento de Pessoal de Nível Superior - Brasil (CAPES) - Código de Financiamento 001. 
tremo. Pessoas bem informadas, como os fundadores de uma ONG que trabalha na redução de resíduos ou o pessoal de alto nível do departamento de limpeza municipal, nunca tinham tido muito a dizer sobre estas fábricas. Estudiosos e amigos locais, que frequentemente me haviam apresentado todo tipo de gente, não puderam me ajudar com um único contato útil nessa área. Sempre que entrevistava um vendedor de sucata e perguntava se ele ou ela vendia materiais recicláveis selecionados a uma fábrica, outro intermediário aparecia constantemente na cadeia, antes de os materiais serem entregues às fábricas. Não havia razão para acreditar que eu, por ser estrangeiro, fosse um obstáculo: pesquisadores indonésios especializados em estudos de resíduos também achavam impenetrável a indústria da reciclagem (Gabriel Andari Kristanto, comunicação pessoal).

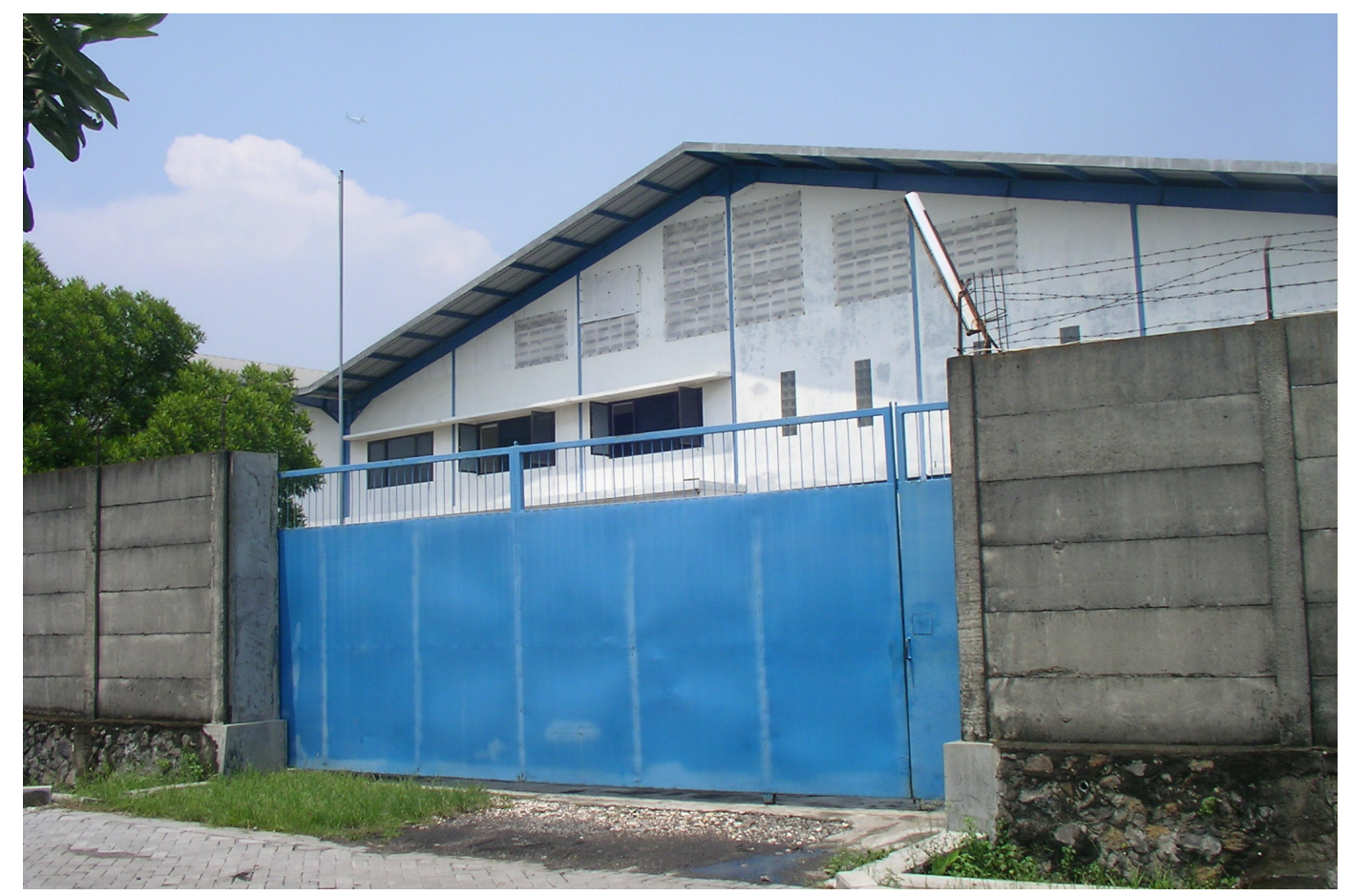

O portão fechado da fábrica. Foto: Freek Colombijn, 2016

O baixo perfil do negócio da reciclagem seria, então, deliberado? Em caso afirmativo, qual seria a razão? A invisibilidade escolhida é, à primeira vista, surpreendente, porque essas fábricas poderiam ser beneficiadas por uma imagem potencialmente positiva como empresas protetoras do meio ambiente. O objetivo deste artigo é abordar a questão para saber se e por que os empresários que reciclam os plásticos na Indonésia optaram por criar este manto de invisibilidade estratégica do público. Como existe uma 
escassez de investigação antropológica sobre as indústrias que produzem e processam plásticos, especialmente em proporção aos abundantes estudos sobre os catadores de materiais recicláveis, também quero encontrar respostas a uma série de questões básicas sobre tais organizações: qual é a lógica empresarial dessas indústrias? De onde provêm os seus materiais? Como é que os materiais que essas indústrias utilizam afetam o processo de produção? Que tipo de produtos fabricam? A quem vendem os seus produtos?

Argumento que considerações comerciais determinam o baixo perfil do negócio da reciclagem. Em geral, os resíduos sólidos são gerenciados efetivamente em Surabaya, porque se trata de um negócio gerido segundo os princípios do mercado, com apenas um pequeno papel atribuído ao governo (Colombijn \& Morbidini, 2017). É possível fazer dinheiro a partir de materiais recicláveis. Precisamente, essa mesma lógica neoliberal significa que a natureza dos produtos reciclados deve ser ocultada, porque os artigos de plásticos reciclados não suscitam as mesmas associações positivas nos seus clientes na Indonésia como ocorre no Norte global. Pelo contrário, eles são tratados com desconfiança. As fábricas no final da cadeia do plástico reciclado dominam o sistema e escolheram estrategicamente ficar fora da vista, permitindo que o custo da vergonha social recaia sobre os catadores de materiais recicláveis e os negociantes de lixo, esses sim, muito mais visíveis.

De 2009 a 2019, foram recolhidos dados para esta investigação, durante um total de 26 semanas de pesquisa etnográfica intermitente sobre questões ambientais urbanas na Indonésia. A maior parte da pesquisa foi realizada na cidade de Surabaya e centrouse em dois grandes temas: na gestão de resíduos sólidos urbanos e nas iniciativas comunitárias para melhorar o meio ambiente no nível dos bairros. Na minha pesquisa sobre os problemas ambientais de Surabaya, concentro-me nos resíduos domésticos, porque esse tema diz respeito a praticamente todos os moradores da cidade e oferece uma boa percepção das forças motrizes por detrás do comportamento ambiental das pessoas. Utilizei a mistura etnográfica padrão de observação (participante), entrevistas qualitativas, encontrando os entrevistados através de amostragem teórica e de "bola de neve", e também o estudo de documentos.

Tentei seguir os resíduos domésticos pela cidade, mas, no começo da pesquisa, eu nunca fui admitido em fábricas que reciclassem tais materiais. Os negociantes de sucata referiam-se sempre a outro elo da cadeia antes de as mercadorias chegarem às fábricas, como comentado acima. A partir de 2016, decidi trabalhar desde o outro extremo da cadeia e ir diretamente às indústrias. Ainda assim, continuou sendo difícil en- 
trar nas fábricas e encontrar seus gestores. Alguns só foram convencidos depois de eu ter feito uma visita surpresa. Outras pessoas consentiram em me conceder uma entrevista após extensas trocas de mensagens de texto, porque, como me explicou o proprietário de uma empresa produtora de artigos de plástico, "eu queria ver se você estava falando sério". Finalmente, consegui conduzir doze entrevistas com pessoas empregadas por empresas que trabalham com plásticos reciclados; algumas dessas conversas foram realizadas com duas ou três pessoas de cada vez e, com duas delas, encontrei-me duas vezes. Com uma única exceção, nunca consegui olhar nas instalações de produção, pois fui acolhido, e efetivamente parado, num escritório perto da entrada. Quatro entrevistas foram realizadas num café, ou seja, fora e longe das instalações da empresa e, embora não saiba por que razão os meus interlocutores preferiram encontrar-se num local tão neutro, o lugar pode ser mais uma indicação do sigilo que rodeia a indústria de reciclagem. É também significativo que as melhores entrevistas tenham sido realizadas com duas pessoas que haviam estudado em países ocidentais e que, por isso, talvez estivessem mais abertos a conversar comigo, e com duas figuras de destaque na Asosiasi Daur Ulang Plastik Indonesia (ADUPI - Associação para a Reciclagem de Plásticos na Indonésia), que tinham interesse em expor os seus pontos de vista através de mim. Esta aparente relutância em dar entrevistas e conversar é incomum em minha experiência como pesquisador, mesmo entre homens de negócios, mas considero que ela transmite esse "baixo perfil" (low profile, no jargão do negócio) escolhido pelos empresários da reciclagem.

Outra possível explicação para o sigilo das empresas é que os gestores e proprietários com quem falei queriam esconder ou as más condições de trabalho ou as violações das regras oficiais de produção. Porém, não encontrei provas desta explicação alternativa. A única fábrica na qual me foi concedida uma visita guiada tinha salões abertos, leves e relativamente limpos, nos quais os trabalhadores me cumprimentaram de uma forma descontraída. Não excluo que as empresas tenham apenas tentado se proteger de olhares curiosos, mas não tenho razões para acreditar que esta tenha sido a principal motivação por detrás dos seus esforços para se manterem discretas. 


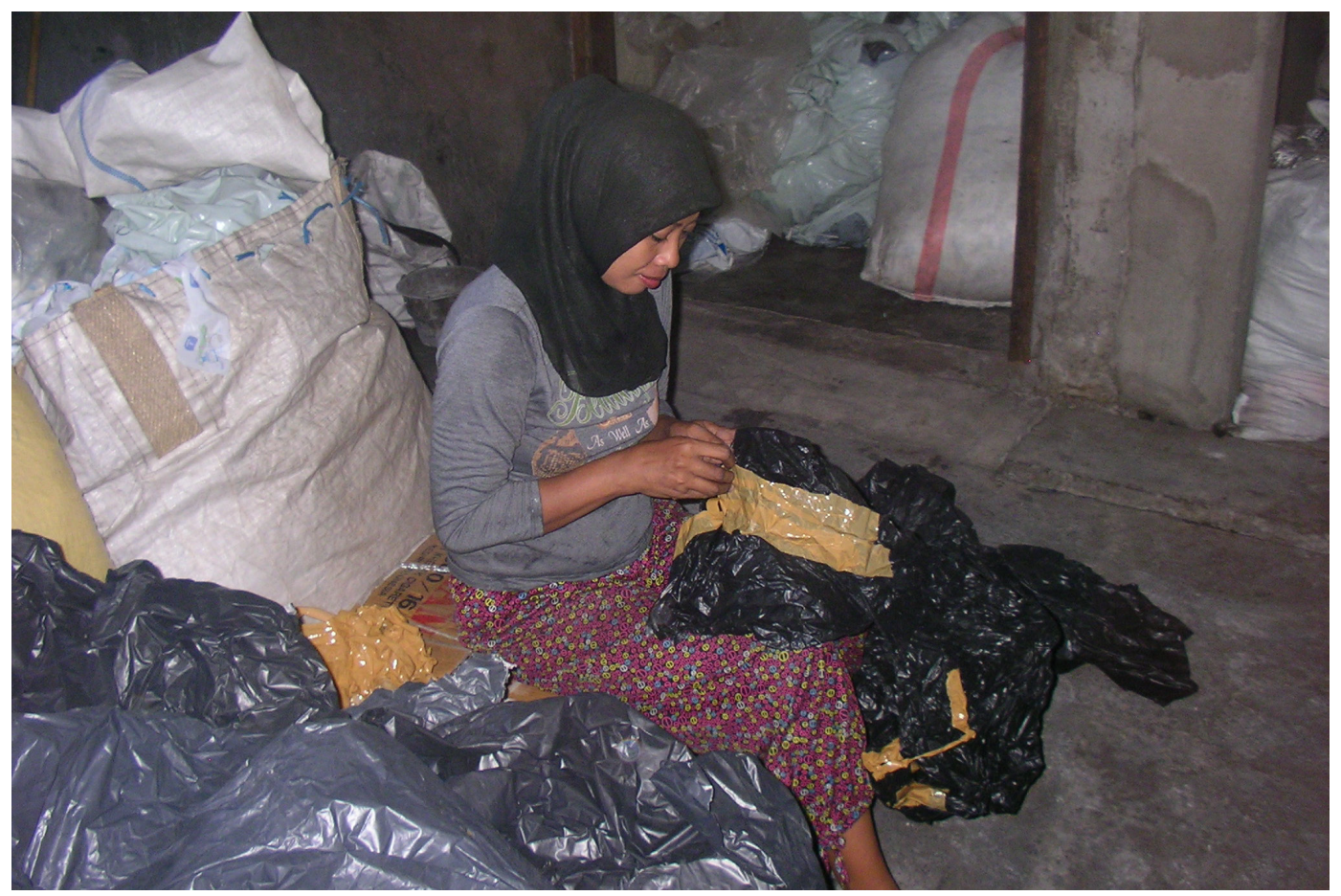

Trabalhadora separa dois tipos de plástico no local de Pak Sarban.

Foto: Freek Colombijn, 2016

\section{Conceitualizando o Comércio de Plásticos Recicláveis}

A reciclagem de plásticos em Surabaya pode ser analisada, utilizando conceitos derivados das teorias acerca da cadeia de valor global (global value chain, no jargão em inglês) ou da cadeia de abastecimento (supply chain, em inglês). O conceito de cadeias de valor global (global value chain) nos ajuda a compreender a globalização dos processos de produção nos quais as empresas transnacionais externalizam funções não econômicas centrais (geralmente, incluindo a produção física) e se concentram na inovação, na estratégia de produtos e no marketing. Uma vez que o processo de produção já não se encontra nas mãos de apenas um produtor, os processos de produção global requerem novas formas de governança a fim de integrar atividades econômicas dispersas espacialmente. O conceito de cadeia de abastecimento (supply chain) coloca a ênfase das análises na direção das transferências econômicas que ocorrem entre produtores e fornecedores e, desse modo, foca menos nas relações de poder desiguais, implícitas no conceito de cadeia de valor global (global value chain).

O controle de cadeias de valor global pode assumir diferentes formas que devem ser estudadas empiricamente em cada caso. As questões-chave a este respeito são: como se estabelecem as normas necessárias para integrar componentes em produtos únicos? 
Como a fragmentação da produção está relacionada à mobilidade de bens, pessoas e conceitos? Quem exerce mais controle sobre a cadeia de valor? Quem colhe o maior número de benefícios (Gereffi, 2005; Gereffi, Huymphrey e Sturgeon, 2005; Crang et al., 2013: 121; Tsing, 2009: 148-149)?

O conceito de cadeias de valor global tem sido aplicado a "cadeias de valor de reciclagem" de resíduos em que "o valor é feito na reciclagem, não apenas através da coleta, mas também através da triagem, separação, preparação e tratamento e, depois, por meio da compactação, embalagem e armazenamento" (Gregson e Crang, 2015: 158). Os plásticos passam por várias transições durante o seu ciclo de vida, de objeto a lixo, a recurso e a ser um novo objeto; o significado e a avaliação dos plásticos muda continuamente ao longo do processo e, com a maioria destas 'traduções' (Tsing, 2015: 162), eles são passados para as mãos de outro ator.

A questão-chave da governança nas cadeias de valor global pode ser colocada sem hesitação também para as cadeias de valor local: "[Se] a produção está cada vez mais fragmentada no espaço geográfico e entre empresas, então, como estas atividades fragmentadas são coordenadas (Gereffi, Humphrey e Sturgeon 2005: 80)?

\section{Plásticos na Indonésia e Surabaya}

Surabaya é a maior cidade da Indonésia depois de Jacarta, a capital nacional. A Indonésia é uma economia considerada recentemente emergente, com números de crescimento econômico ininterrupto desde a crise asiática de 1989. O crescimento econômico significa uma classe média em rápida expansão, que aspira a um maior consumo e produz volumes crescentes de resíduos, a maior parte dos quais, cada vez mais, são produtos de origem não orgânica. Sem um tratamento adequado dos resíduos municipais, a cidade pode tornar-se inabitável. Os plásticos são um sinal da crescente prosperidade da Indonésia.

A coleta e a eliminação de resíduos sólidos em Surabaya é um trabalho conjunto da prefeitura e de muitos agentes privados, desde catadores de materiais recicláveis a grandes fábricas de processamento de recicláveis e de uma empresa contratada (terceirizada) pelo município para gerir o aterro. A recolha de resíduos sólidos urbanos começa no nível do bairro. Um bairro é responsável pela coleta dos seus próprios resíduos, e as residências pagam em conjunto a um homem ou uma mulher que os recolhe de porta em porta. O catador deposita os resíduos num local temporário de coleta (Tempat Pembu- 
angan Sampah Sementara, TPS) ou em uma estação de transferência de resíduos; existem cerca de 170 desses locais em Surabaya. A partir daí, o município assume a responsabilidade, e os caminhões do departamento de limpeza municipal transportam os resíduos dos locais de descarga temporária para o destino final (Tempat Pembuangan Sampah Akhir, TPA), o aterro sanitário Benowo, nas franjas do município. O aterro é operado por uma empresa privada, PT Sumber Organik, que é paga por unidade de peso pelo governo local.

A realidade é muito mais complicada e diversa do que o sistema formal acima descrito. Outra variável é lançada pelo mercado de recicláveis, para o qual o lixo doméstico não é tratado como algo a ser descartado, mas é, sim, considerado como um produto potencial. Os catadores (pemulung, na língua local) operam ao longo da cadeia, procurando resíduos vendáveis: plásticos, papel, papelão, metais, garrafas de vidro, latas, etc. Os catadores vão de lixeira em lixeira, tanto nas vizinhanças quanto ao longo da rua. As pessoas que catam e recolhem os resíduos dos bairros dividem o seu tempo entre essa coleta e a sua triagem nos locais de descarga temporária. Outros catadores operam no aterro sanitário ou no local de eliminação final de resíduos. Alguns bairros, com uma forte consciência ambiental, criaram uma espécie de banco de resíduos, no qual o lixo doméstico é recolhido e separado.

Os materiais recicláveis são comprados por comerciantes de lixo (pengepul). Alguns negociantes de lixo são encontrados espalhados pela cidade, mas outros estabeleceram negócios perto do aterro; todos empregam trabalhadores que separam os resíduos em categorias de granulação mais fina. Os próprios negociantes de lixo constituem uma rede complexa. Alguns são atacadistas que compram coisas de comerciantes de menor dimensão. Outros são da mesma escala, mas trocam bens, cada um especializado num tipo de reciclagem. Os plásticos passam por várias mãos, cada qual os limpa progressivamente e os divide em grupos mais específicos, até que, finalmente, sejam vendidos às fábricas que os processam. O que aqui esbocei é apenas um quadro rudimentar e, se fizermos um zoom, a impressão geral será a de um sistema de grande complexidade. 


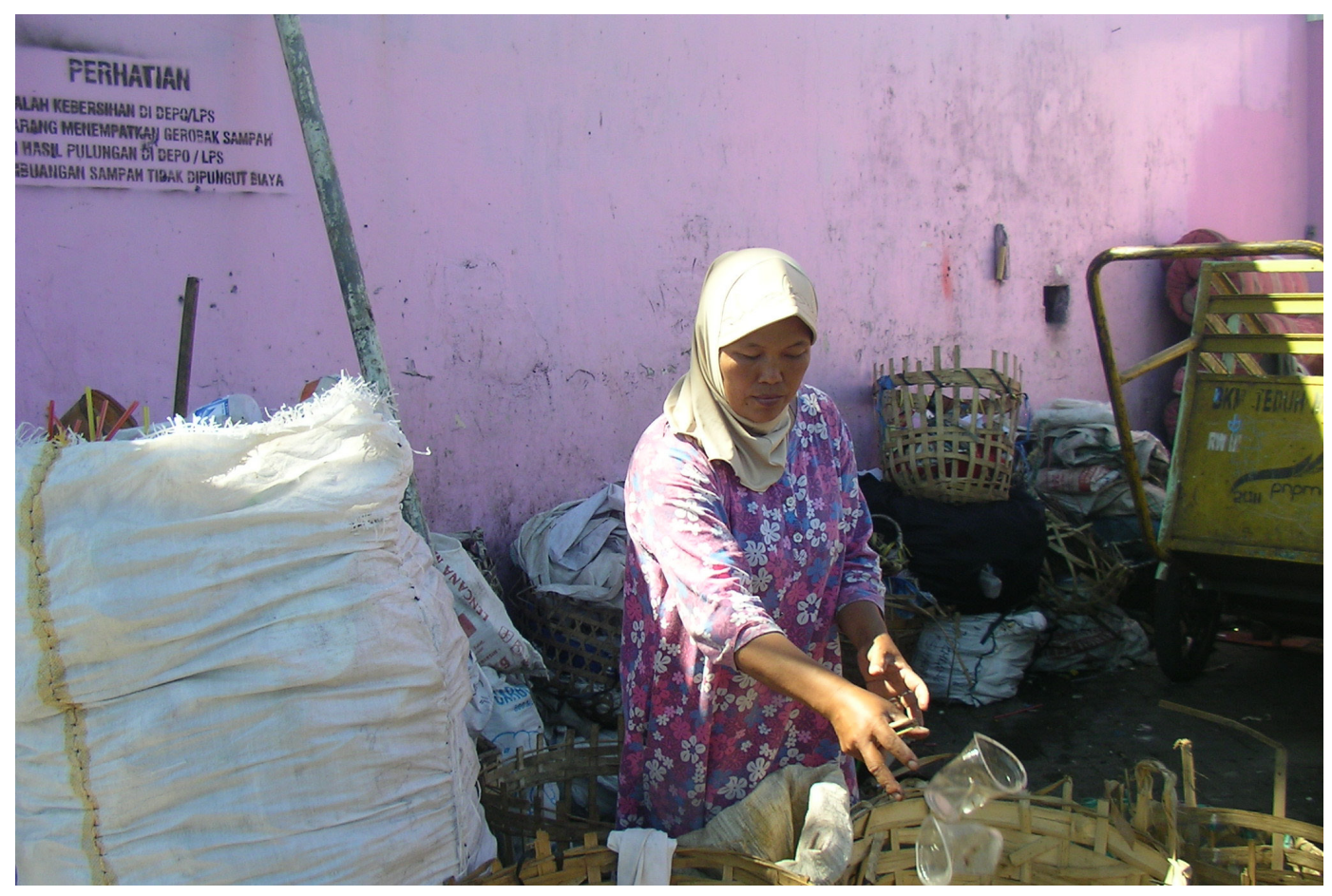

Trabalhadora em um ponto de coleta temporária; a área murada separa o local de seu entorno. Foto: Freek Colombijn 2014

Apenas estimativas aproximadas sobre a quantidade de plásticos reciclada estão disponíveis. Diferentes fontes apresentam números bastante díspares entre si. As estimativas são aproximadas, devido a medições pouco confiáveis e também porque Surabaya não é um sistema fechado, e os resíduos plásticos não tratados podem ser importados e exportados. Segundo um relatório do Banco Mundial (2018: 19), Surabaya gera 2.483 toneladas de resíduos por dia, das quais 1.478 toneladas $(59,5 \%)$ são levadas para o local de depósito final. A mesma fonte declara que 84,5 toneladas $(3,7 \%)$ são tratadas por coletores de resíduos (e os restantes $37,1 \%$ dos resíduos são deixados "sem tratamento", ou seja, acabam em rios, ao longo de linhas férreas, são queimados ou eliminados de alguma outra forma). Judianti (2007) apresenta porcentagens mais elevadas de plásticos reciclados; o autor constatou que, em sete locais de depósito temporário, em média, $40 \%$ do peso dos plásticos foi separado para revenda pelos catadores, mas também estimou que $25 \%$ dos plásticos dos resíduos domésticos já haviam sido separados (presumivelmente, na sua maioria, pelas próprias unidades familiares) antes de os resíduos chegarem aos locais de coleta temporária. 
A Economia da Cadeia de Fornecimento (supply chain) de Plásticos Recicláveis em Surabaya

Crang et al. (2013: 13) observam que, no negócio dos recicláveis, o valor não é adicionado à cadeia, mas sim "extraído" dela, e esta extração está ligada às propriedades materiais dos produtos no final de vida. A materialidade dos resíduos não é homogênea, e a realização de valor capitaliza esta heterogeneidade de materiais. "Para se extrair valor, é necessária uma triagem cada vez mais fina", e a capacidade de distinguir tipos de resíduos "está intimamente guardada, pois é a base de uma reavaliação lucrativa" (Crang et al. 2013: 18). A triagem de resíduos é, de fato, uma habilidade. Certa vez, estava num barracão onde trabalhadores separavam lixo para um negociante e utilizavam cerca de 18 cestos para plásticos diferentes. Eu, porém, não conseguia distinguir um do outro.

Este tipo de valor que é adicionado numa cadeia de reciclagem (recycle chain) difere de acrescentar valor a um produto que sobe numa cadeia de valor global normal, em que diferentes recursos são reunidos em componentes, em etapas sucessivas, o que termina por resultar no objeto final, seja esse um telefone celular ou um alimento processado. Numa cadeia de reciclagem, pelo contrário, o valor é acrescentado não pela montagem, mas pela atividade oposta, ou seja, pela separação ou pela triagem. A classificação dos resíduos em categorias de granulação mais fina torna esses materiais mais valiosos. Quando os bens são reciclados, não são movidos para trás na cadeia de abastecimento, ou o que se chama uma cadeia de valor invertida (reversed value chain, em inglês), mas sim para a frente na cadeia, acrescentando-lhe um novo tipo de valor.

Embora a triagem em categorias mais finas seja o valor acrescentado mais importante de uma cadeia de reciclagem, essa não é a única atividade. A limpeza dos resíduos também acrescenta valor. Num determinado ponto da cadeia, observei homens cuja única tarefa era rasgar sacos de plástico para que o lixo caísse fora e, assim, os sacos triturados pudessem ser mais facilmente lavados na fase seguinte. $\mathrm{O}$ valor agregado era mínimo (tal como o pagamento), mas, por muito pequeno que fosse, os trabalhadores buscavam alguma rentabilidade com os plásticos.

A atividade de separação dos resíduos em categorias cada vez mais refinadas deve ser completada com um processo semelhante de fluxos de resíduos que se juntam em volumes progressivamente maiores, separados em uma determinada categoria. Este papel de um coletor, acumulando volumes cada vez maiores, é o oposto ao de um distribuidor numa cadeia de abastecimento regular. 
As duas tarefas de separação dos resíduos em categorias mais refinadas e de coleta de volumes cada vez maiores de um recurso em especial estão frequentemente em um mesmo lado. Isto começa com as pessoas que coletam os resíduos de porta em porta nos bairros, e são elas também as primeiras a fazer a triagem em grandes categorias de resíduos. No elo seguinte da cadeia, os compradores de sucata pagam por essas categorias amplas de resíduos que os catadores selecionaram, mas também empregam outros trabalhadores para efetuar uma triagem mais fina. Ghisellini, Cialani e Ulgiati (2016: 19) utilizam os termos 'catadores' e 'decompositores', e Tsing (2009: 169) fala de 'depenadores', 'compradores' e 'a granel ${ }^{3,}$ (no negócio dos cogumelos selvagens) para descrever alguns destes trabalhadores, mas penso que precisaríamos de um vocabulário ainda maior, se quiséssemos descrever corretamente todas as diferentes ocupações que encontrei no campo.

O caminho mais curto de um pedaço de plástico, por exemplo, o de uma garrafa plástica, seria começar por um catador que o retira do lixo e o vende a um comprador de sucata; este, por sua vez, vende o produto a um triturador, que entrega esses pedaços de plástico a uma fábrica que os transforma em pellets. Estes são eventualmente vendidos a uma empresa que fabrica um novo produto de plástico. Na prática, esta cadeia hipotética, composta por cinco atores diferentes, na realidade, quase nunca funcionará da forma descrita acima. Normalmente, os negociantes de sucata (em inglês, junk-dealers) comercializam e trocam entre si produtos de seus interesses específicos. Há também diferentes etapas, que variam desde os pequenos aos grandes negociantes de junk-dealers. As fábricas que produzem pellets estão, portanto, muito afastadas do trabalho "sujo" dos catadores e dos trabalhadores do comprador de sucatas que selecionam os resíduos.

Um ator pode combinar vários papéis. Pak Sarban é um bom exemplo de um trabalhador multitarefa. Eu havia encontrado o seu endereço na internet e, depois de termos trocado vários e-mails, marcamos um encontro. Em frente à sua empresa, comecei a duvidar de que estava no endereço correto, porque a entrada era uma fila de pequenas lojas, e a sua parecia abandonada. Um amigo que me havia acompanhado pegou o celular e telefonou para lá; felizmente, então, a porta se abriu. Atrás da entrada muito modesta havia um escritório e três salões de vários tamanhos nos quais os plásticos eram armazenados e processados.

\footnotetext{
${ }^{3}$ No original, Tsing utiliza o termo "bulkers", em inglês. Nota da tradutora.
} 
O principal negócio da Pak Sarban é a produção de pellets a partir de sacos de plástico. As máquinas são operadas manualmente. Os sacos de plástico são atirados para uma máquina que aquece o material e o extrai para fora em longos fios de plástico que são arrefecidos numa banheira comprida, cheia de água. Após este banho, o "espaguete" de plástico é cortado em pellets. Pak Sarban declarou que 90\% dos seus ganhos resultam da produção de pellets e que $10 \%$ têm origem na venda de material plástico que comprou dos negociadores de sucata, mas não utilizado. No entanto, grande parte do material, digamos, 70\%, já não provêm de negociadores de sucata. Este material é utilizado na fabricação de embalagem comprado diretamente de outras empresas. O seu trabalho não se limita ao comércio de plásticos, mas inclui também a triagem de granulado fino, que normalmente é feita por um negociante de sucata: quando visitei a fábrica, duas mulheres rasgavam a fita adesiva do plástico, tratando, assim, de uma etapa da triagem de materiais que normalmente é feita numa fase anterior da cadeia. Pak Sarban tem, portanto, três empregos: produz pellets, classifica os resíduos e negocia no ramo de resíduos de plástico.

Crang et al. (2013: 13-15) afirmam que o fornecimento de produtos em fim de vida, dos quais podem ser extraídos recursos, é relativamente não elástico. Uma elevada demanda por produtos recicláveis não conduz rapidamente a uma maior oferta. $\mathrm{O}$ "ímpeto é geralmente de alguém se livrar de coisas existentes e indesejadas. Em outras palavras, a oferta vem antes da procura". Embora esta afirmação seja correta para roupas usadas, e talvez para o papel, o papelão e o vidro; no caso dos plásticos é diferente, como me foi explicado pela primeira vez em detalhe por Pak Nordin.

Pak Nordin produz grandes objetos de plástico, como barris de água, caixotes de lixo e caiaques, para os quais utiliza sempre uma mistura de plásticos feitos de petróleo bruto e plásticos reciclados. Se ele produzisse os objetos apenas a partir de plástico novo, o custo seria proibitivo, mas ele está limitado a um máximo de 50\% do plástico reciclado mais barato, uma vez que este material é menos elástico e quebradiço. Quando o entrevistei, em março de 2016, época na qual os preços do petróleo eram baixos, ele utilizava $90 \%$ do plástico original, mas quando nos encontramos novamente, em fevereiro de 2017, ele estava utilizando uma mistura de 50/50.

Nem preciso dizer que o preço dos pellets de plástico reciclado deve ser sempre inferior ao do plástico feito a partir do petróleo bruto. O preço do plástico reciclado não é determinado pela oferta nem pela procura, mas sim pelo preço do plástico alternativo (o plástico novo). Pak Nordin diz que a diferença habitual de preço dos seus recursos é 
de IDR 5.000/ $\mathrm{kg}^{4}$, mas, no início de 2017, quando o petróleo estava em um nível de valor baixo e, consequentemente, o plástico novo era também muito barato no mercado, o preço do plástico reciclado não podia manter a diferença de IDR 5.000/kg, necessária para permanecer competitivo.

Dois outros informantes me disseram que a produção de plástico reciclado havia sido reduzida, mas que tal escassez não faria subir novamente seu preço, enquanto o petróleo continuasse barato. Os catadores de materiais recicláveis ao longo da cadeia de abastecimento devem ter sido expulsos do trabalho ou foram trabalhar com outros materiais recicláveis. Os produtores de plásticos reciclados têm poucos meios de se proteger contra o baixo preço do petróleo, exceto, transferindo o peso da cadeia de abastecimento para os catadores e para os comerciantes de lixo. Ironicamente, os produtores de pellets feitos de plástico reciclado são, assim, indiretamente apoiados pela concorrência do plástico virgem para manter baixo o preço do plástico reciclado. Na pior das hipóteses, uma queda do preço global do petróleo poderia, em última análise, fazer parar a produção de plásticos reciclados.

\section{A cadeia de abastecimento de plásticos recicláveis e o movimento de resí-} duos

A maioria dos estudos de cadeias de valor global (global value chains, em inglês) tomam como certo que exista um fluxo unidirecional entre o Norte global e o Sul global. A produção tem lugar no Sul, o consumo, no Norte, e as atividades mais rentáveis nas estratégias de marketing e de empresa têm lugar no Norte. A cadeia termina com o consumo dos bens produzidos, e os bens em fim de vida tornam-se resíduos. Crang et al. (2013: 14) desafiam este pressuposto básico e fazem notar que o presumível fim da cadeia de abastecimento é o início de uma nova cadeia de recicláveis. E surpreenderam-se que a cadeia global de reciclagem não apenas inverte a direção do comércio, ela também desmonta literalmente os produtos. Em termos de volume, o comércio de resíduos tem maior fluxo do Norte para o Sul (Crang et al., 2013: 12; Gregson e Crang ,2015: 153, 160).

\footnotetext{
${ }^{4}$ Nota da tradutora: IDR é a sigla internacional para a moeda da Indonésia. No próprio país, no dia a dia, utilizam a palavra Rupiah (significa "prata”, em Sânscrito). Para saber mais sobre a moeda na Indonésia, checar https://en.wikipedia.org/wiki/Indonesian_rupiah
} 
Embora as noções de cadeias de valor, cadeias de abastecimento, ou cadeias de reciclagem, sejam úteis, o debate sobre se os fluxos vão de Norte a Sul ou vice-versa, com ideias concomitantes sobre a hegemonia do Norte, são irrelevantes para a minha história. Os produtores de plásticos recicláveis utilizam qualquer material que puderem, se conseguirem por ele um bom preço, independentemente da sua origem. Pak Nordin, o proprietário de uma fábrica que produz grandes objetos de plástico, certa vez comprou uma grande carga de plástico reciclado de Dubai, do Brasil e da Coreia do Sul, quando essa the foi oferecida a um preço baixo, mas não encontrou diferenças nem na compra nem na qualidade em relação ao plástico de fontes indonésias. Um ponto semelhante foi observado pelo gerente de uma fábrica produtora de papelão a partir de papel reciclado, que adquiriu material de fornecedores locais de distantes lugares da Indonésia, como o Médio Oriente e a Europa. As diferenças de qualidade eram mínimas e também o fato de o papel ter sido molhado para torná-lo mais pesado; os europeus eram tão ruins como os fornecedores locais.

A cadeia de resíduos em Surabaya difere de outros estudos de cadeias de valor global de materiais recicláveis. O lixo sobre o qual estou tratando não é normalmente um bem de consumo utilizado no Norte e desmontado no Sul, como telefones celulares, computadores e televisões. O grosso desse lixo é constituído por artigos simples, produzidos localmente: resíduos orgânicos, papel, latas, garrafas de plástico e inúmeros sacos plásticos. É um caminho relativamente pequeno do produto no final de vida até a fonte de recurso utilizável, muito mais curto do que o desmantelamento de um computador.

As fábricas que produzem pellets só fazem negócios com grandes fornecedores, entregando, pelo menos, 1 ou 2 toneladas de plásticos recicláveis de cada vez. Pak Sarban, que produz pellets a partir de sacos de plástico velhos, negocia com cerca de 40 varejistas, que vendem de 1 a 20 toneladas de material por mês, mas o preço varia em função do volume: quanto maior for o volume que lhe é oferecido, mais disposto ele está a pagar por quilograma. Ele aumentou o valor, de 7,000/kg de IDR para garrafas plásticas de polipropileno (PP) limpas, para IDR 500-1,000/kg para volumes maiores, uma diferença de preço de 7-14\%. Não vale a pena, para um pequeno negociante de sucata que vive a alguma distância, transportar uma pequena quantidade para a fábrica de Pak Sarban, porque ele ou ela receberá um preço baixo. Este sucateiro achará mais rentável vender o seu produto localmente a outro sucateiro, que trabalhe com volumes maiores ou que tenha meios para transportar volumes maiores, ainda que esteja localizado mais longe. Este segundo sucateiro ainda terá lucro, apesar do custo de transporte, 
porque Pak Sarban estará disposto a pagar-lhe um preço mais elevado. Curiosamente, o próprio Pak Sarban estava bem ciente da cadeia de abastecimento e falava literalmente

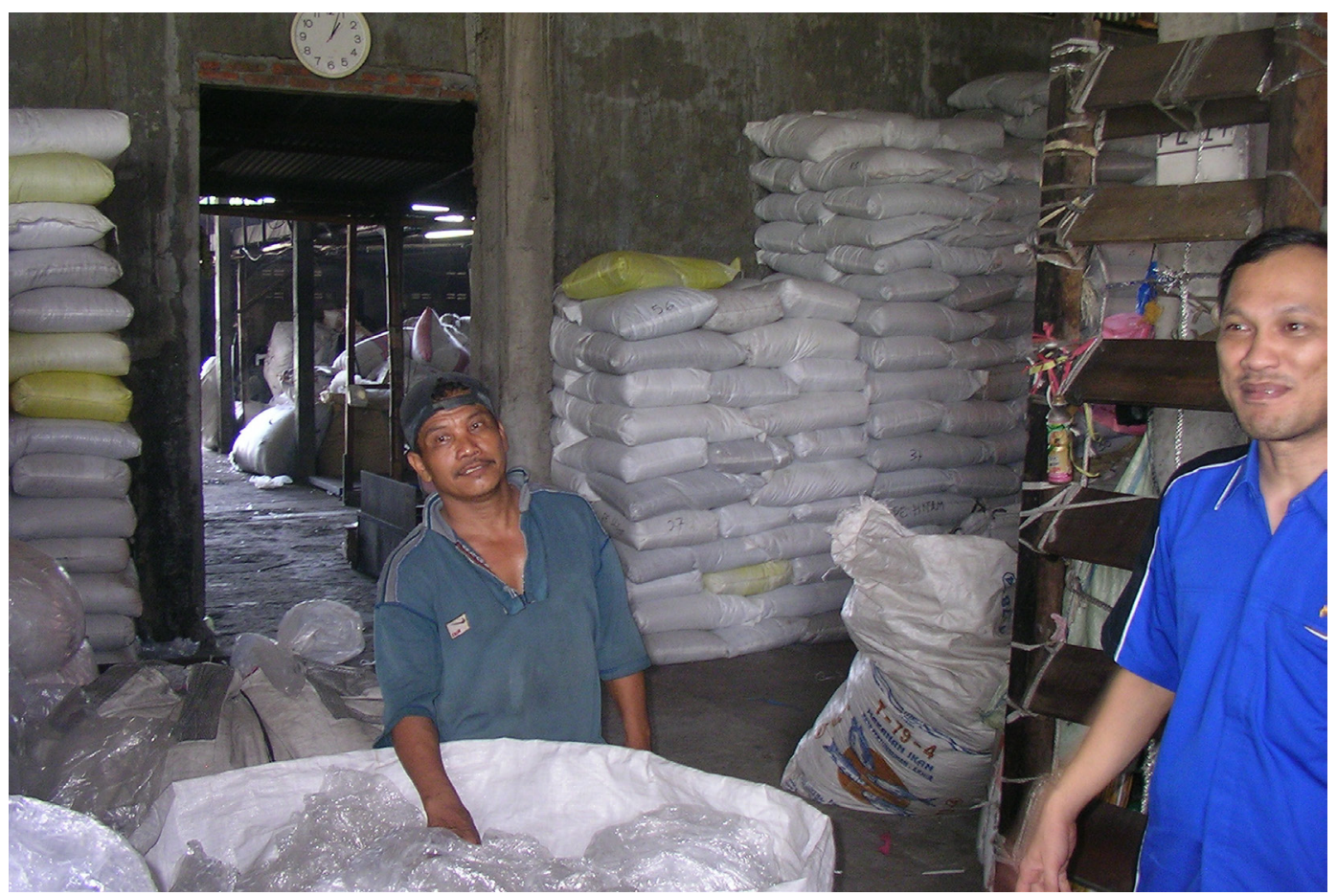

Unidade de produção de uma fábrica que produz pellets de plástico Foto: Freek Colombijn 2016

de uma "cadeia".

\section{Governança da cadeia de abastecimento}

Todas as cadeias de valor global enfrentam os desafios de que "[se] a produção está cada vez mais fragmentada no espaço geográfico e entre empresas, então, como são coordenadas estas atividades fragmentadas? (Gereffi, Humphrey e Sturgeon, 2005: 80). Gereffi, Humphrey e Sturgeon (2013: 85-86) parecem ver este desafio, antes de tudo, como um problema prático de gestão para o qual a solução depende de três fatores: a complexidade da transferência de informação e conhecimento necessários, a medida em que a informação pode ser codificada e as capacidades dos fornecedores. Destes três fatores, a complexidade da informação necessária é, sobretudo, um problema tecnológico e ultrapassa o âmbito deste artigo, mas a codificação da informação e as capacidades avaliadas dos fornecedores são problemas de ordem mais social.

A codificação da norma deve ser feita de um modo que possa ser facilmente apreendida, mesmo pelos fornecedores que talvez não sejam alfabetizados. Apresentar 
amostras do material é a forma mais comum de codificar a norma, e eu encontrei-a em três empresas diferentes. Por exemplo, no fundo da sala, onde um produtor de plásticos recicláveis recebe os seus visitantes, havia mais de 100 frascos de vidro com amostras do material aceito (pedacinhos de plásticos em várias cores) e outros com amostras dos pellets por ele produzidos. A sua transparência com relação às amostras, depois de eu ter tido acesso às instalações, contrasta com o sigilo que rodeia o local de produção. Embora este seja o maior produtor de plásticos recicláveis de Surabaya, passei dirigindo duas vezes por sua porta, duas vezes antes de conseguir achar a entrada, porque o complexo está rodeado por uma parede alta, e não dá indicação alguma do que se passa no seu interior.

Outra forma de um especialista poder reconhecer o tipo de plástico e a sua qualidade é mordendo-o para testar a sua elasticidade. Um comerciante que trabalhava no ponto de venda de uma grande empresa no centro da cidade tinha feito disto um hábito. Ao longo da minha entrevista com ele, estava constantemente colocando pellets entre os seus dentes da frente. Uma faca com uma ranhura era, sem dúvida, a sua peça de equipamento mais importante. Ele enfiava a faca em sacos contendo pellets para mostrar aos visitantes e posteriormente mordia esses pedaços de plásticos/pellets.

O padrão exigido pelas fábricas é transmitido ao longo da cadeia de fornecimento de materiais recicláveis. Um moedor especializado em garrafas de plástico adquiriu e também passou a separar material, utilizando os tipos e cores de plástico codificados pelas fábricas. As tampas azuis eram separadas com outras azuis, e as vermelhas, com as vermelhas. Anteriormente, na cadeia de abastecimento de recicláveis, eu havia observado operários que trabalhavam para negociantes de sucata, fazendo divisões semelhantes, mas menos refinadas.

A codificação das normas não é garantia de que os comerciantes, ao longo da cadeia de reciclagem, mantenham o padrão exigido. Dependendo de como os fornecimentos estejam poluídos, as fábricas que produzem pellets a partir de plásticos reciclados têm uma taxa de recuperação de $90 \%$ a $50 \%$. Se as fábricas quiserem minimizar a perda de material inútil, outro fator na gestão da cadeia de abastecimento é a avaliação da capacidade dos fornecedores.

Avaliar a qualidade dos fornecedores não é, infelizmente, tarefa fácil, e o comércio de materiais recicláveis oferece uma "enorme possibilidade de oportunismo" (Crang et al. 2013: 19). Para empresários bem-intencionados há sempre um compromisso entre a pureza dos materiais extraídos e o investimento em mão de obra e capital ne- 
cessário(s) para atingir este padrão (Gregson e Crang, 2015: 167). Os fornecedores sem escrúpulos pesam as hipóteses de serem apanhados, por exemplo, quando escondem plásticos poluídos no fundo de uma entrega. Cientes das suas práticas pouco honestas, as empresas que produzem pellets a partir de materiais recicláveis, e as empresas que utilizam esses produtos, sabem da existência de fraudes. Pak Nordin desejava que houvesse uma auditoria independente dos produtores de pellets reciclados, mas não circula dinheiro suficiente na certificação de plásticos para justificar uma investigação por parte da Corruption Watch.

Três funcionários do maior produtor de plástico reciclado estavam especialmente preocupados com os materiais obtidos a partir de garrafas que haviam contido líquidos tóxicos, tais como inseticidas e germicidas, medicamentos, ou restos humanos em plásticos utilizados para fins médicos. Alegaram que existem testes fáceis. Por exemplo, supostamente, a estrutura do plástico muda quando uma garrafa contém material tóxico. De vez em quando, eles recolhem uma amostra dos recursos de plástico que lhes são oferecidos e queimam alguns deles. Se o plástico queimado tiver um cheiro nocivo, presume-se que seja venenoso. Num outro teste, jogam a amostra em água fria; se afundar, acham que é boa, mas, se continuar a flutuar, o plástico é tóxico. Ao ouvir as suas explicações, não pude deixar de ver uma semelhança com os ensaios históricos das bruxas europeias, mas talvez não deva questionar a confiabilidade destes métodos, e acreditar em sua expertise.

Em contraste com o escrito por Gereffi, Humphrey e Sturgeon (2013), para Crang et al. (2013), o estudo da governança não é um problema de gestão prática, mas se trata de uma questão de poder desigual. Crang et al. (2013) e Gregson e Crang (2015: 164-166) concluem que, nas cadeias de abastecimento global de bens de consumo, as empresas líderes estão geralmente no controle, mas, nas cadeias de abastecimento de materiais recicláveis, os atores, que atuam no meio dela é que a governam. Neste ponto, quero fazer um apelo para que nenhuma suposição sobre a governança das cadeias de reciclagem seja feita de antemão, e a questão sobre quem as controla deve ser estudada empiricamente. Com base na codificação por amostras, a minha conclusão é de que as fábricas que produzem pellets têm o maior controle sobre a cadeia.

Anna Tsing (2009) refletiu sobre as relações de poder desiguais no que ela chama de "capitalismo da cadeia de abastecimento". Ela argumenta que os trabalhadores foram privados dos seus direitos duramente conquistados anteriormente por dois mecanismos interligados: o papel das classificações sociais não econômicas - das quais trata- 
rei mais adiante - e a subcontratação do trabalho representado como empreendedorismo independente.

O trabalho de subcontratação desempenha um papel importante na cadeia de reciclagem de plásticos em Surabaya. As empresas produtoras de pellets fazem um esforço para manter os seus fornecedores a distância. As entregas de material são pagas no local, em dinheiro, e nenhuma relação permanente é desenvolvida através da troca de crédito ou de transferências bancárias. Os compradores e vendedores de entregas, muitas vezes, não sabem o nome um do outro.

O controle sobre a cadeia de abastecimento é também visível no número limitado de fornecedores com quem as fábricas querem negociar. Só aceitam recursos em grandes quantidades, forçando os fornecedores a aceitar a negociação com grandes empresários que compram os suprimentos de pequenos negociantes de sucata. As fábricas simplesmente recusam pequenas quantidades ou pagam um preço por unidade de peso inferior para volumes menores.

Um corolário da subcontratação é que as grandes empresas produtoras de pellets não parecem se preocupar muito com os problemas dos seus fornecedores. A sua falta de empenho é demonstrada pelas histórias de dois trituradores que foram enganados pelos seus próprios fornecedores. O primeiro triturador faliu, quando um vizinho que transportava dois caminhões carregados de plástico reciclável moído para uma fábrica fugiu com o dinheiro. O outro triturador sofreu o mesmo destino, quando uma fábrica rejeitou a sua entrega. Ele havia comprado o material e verificado a camada superior, mas o seu fornecedor havia ocultado material sujo por baixo. O tratamento cruel dos trituradores mostra que são as fábricas que têm o poder de decidir quem é chamado de "capaz" e quem é "incapaz".

Anna Tsing (2009: 148) faz notar que, embora várias empresas sejam disciplinadas dentro de uma cadeia de abastecimento, a autonomia de empresários ostensivamente independentes foi legalmente estabelecida. Quando os fornecedores aprendem a considerar a si próprios como agentes independentes de risco, no lugar de reputar-se como trabalhadores, a cadeia de abastecimento pode levar à "superexploração" (Tsing, 2009: 148, 167). Esta ficção de empreendedores independentes em Surabaya é claramente visível perto do início da cadeia de abastecimento. Os catadores do aterro mencionam a sua liberdade como uma razão importante para terem escolhido este trabalho. Muitas vezes, contrastam o trabalho de catador com uma antiga atividade numa fábrica na qual tinham de trabalhar de acordo com o relógio e obedecer a um patrão. No aterro, 
no entanto, estão, na realidade, vinculados ao coletor que lhes dá um pagamento adiantado, que deve ser reembolsado em espécie, pelo que, dificilmente, podem ser chamados empresários independentes. Se esta ficção de empreendedorismo independente também deve ser chamada de um caso de superexploração, é para mim uma questão ainda em aberto. Os catadores de materiais recicláveis levam vidas melhores do que a que os meios de comunicação social normalmente sugerem, e eu não os chamaria de "explorados".

A ficção do empreendedorismo independente adapta-se muito bem às fábricas. Referindo-se ao Wal-Mart como um caso exemplar de cadeias de fornecimento capitalistas, Tsing (2009: 156) demonstrou que a empresa não quer controlar nem os acordos laborais nem as práticas ambientais dos seus subcontratados. Além disso, mesmo "as empresas mais "socialmente conscientes" são capazes de afirmar que, apesar de seus melhores esforços, são incapazes de forçar o cumprimento de seus elevados padrões éticos" (Tsing 2009: 163). Este argumento pode ser aplicado tão apropriadamente à cadeia de fornecimento de recicláveis como ao Wal-Mart. As fábricas acham conveniente não ter um conhecimento demasiadamente detalhado sobre o modo de funcionamento dos trituradores, dos comerciantes de lixo e dos catadores de materiais recicláveis. Se as fábricas lavassem os plásticos antes de utilizá-los, os custos do tratamento das águas residuais seriam proibitivamente elevados do ponto de vista empresarial. Um triturador, numa aldeia, pode descarregar as águas residuais sem tratamento num rio ou, quando ele tem um tanque para limpar as águas residuais, a lama é utilizada para elevar o nível dos campos agrícolas, de modo que, no final da conta, a poluição acaba despejada na natureza. Pak Jacky, proprietário de uma grande fábrica que produz pellets a partir de material reciclado, pensa que os trituradores são, nas suas palavras, "safados" e também que o governo faz vista grossa ao que está acontecendo para proteger as oportunidades de emprego. O próprio Pak Jacky está feliz por comprar o material barato dos trituradores e observa que eles são "homens de negócios, não ambientalistas".

As diferentes formas de governança da cadeia de abastecimento beneficiam todas as fábricas no final da cadeia. Elas mantêm o controle sobre a cadeia através da codificação de normas e pelo seu poder de determinar qual triturador ou qual negociante de sucata é competente e qual não é. Através da subcontratação da coleta e triagem de resíduos, aumentaram a sua própria invisibilidade e distanciaram-se com sucesso de atividades que são socialmente desaprovadas. Manter uma distância dos fornecedores 
que se imaginam empresários independentes abre a porta para a superexploração dos catadores e dos negociantes de sucata

\section{A Imagem Pública de Plásticos Recicláveis}

Anna Tsing argumentou que a superexploração de pretensos empresários independentes é mais provável de ocorrer quando as pessoas que ocupam nichos específicos numa cadeia de fornecimento são definidas através da interseção de fatores "não econômicos", como gênero, raça, etnia, nacionalidade, religião, sexualidade, idade e estatuto de cidadania". A superexploração depende, por definição, destes fatores não econômicos e é, então, "maior do que se poderia esperar dos princípios [puramente] econômicos gerais" (Tsing 2009: 158).

Este tipo de hierarquia não econômica, que disciplina a força de trabalho numa cadeia de fornecimento de recicláveis, está ausente da gestão de resíduos em Surabaya. Os catadores de materiais recicláveis, e aqueles que trabalham para os negociantes de lixo, não são diferentes das pessoas que se encontram mais acima na cadeia em termos de etnia, nacionalidade, religião, cidadania ou idade. Embora os homens possam dominar os escalões superiores, as fases iniciais da cadeia de abastecimento são ocupadas por homens e mulheres em número igual. Na verdade, a coleta de lixo é notavelmente neutra em termos de gênero, e frequentemente feita por um casal.

No entanto, por um lado, as pessoas que lidam com os resíduos são destacadas e estigmatizadas: o seu trabalho é poluído, no sentido utilizado por Mary Douglas (1966). O plástico reciclado é poluente, e as pessoas que processam os resíduos são, por extensão, também simbolicamente poluídas. Mais de uma vez, os gestores das fábricas que me ofereceram algo para beber recusaram-se a beber com um canudo de plástico, um hábito comum na Indonésia, receando que o canudo tivesse sido produzido a partir de material contaminado (resíduos médicos ou fezes). Por outro lado, o plástico que é feito de petróleo bruto é chamado em indonésio de 'plastik murni' (plástico puro, ou plástico não adulterado), e a expressão inglesa 'virgin plastic' é também utilizada para o plástico feito com esse material. Quando mesmo as pessoas que produzem plástico a partir de material reciclado têm uma atitude tão negativa, não surpreende que o plástico reciclado tenha um estatuto baixo na sociedade em geral.

Ao contrário do Norte global, onde as pessoas estão dispostas a pagar mais por um objeto feito de material reciclado, a fonte do material não é um atrativo de venda na Indonésia. Como me explicou um gerente de uma empresa produtora de pellets: quando 
os consumidores veem o símbolo internacional do material reciclado (três setas que formam os lados de um triângulo equilátero), assumem imediatamente que o objeto é de má qualidade. Os consumidores preocupados com o meio ambiente, e que têm uma ideia positiva sobre a reciclagem, ainda se recusam a pagar mais por esses produtos, porque acham que o produtor que trabalha com recicláveis está trapaceando, fazendo algo errado, e que se apropriou indevidamente de tal símbolo (o utilizado internacionalmente para produtos reciclados). Num tal ambiente, a natureza reciclada dos objetos de consumo é, portanto, melhor quando escondida dos olhos do público. Como concluiu Pak Nordin: "Os produtores de objetos de plástico mentem um pouco" sobre a utilização de plástico reciclado; e os consumidores querem artigos baratos e "não querem saber" sobre a origem reciclada do material.

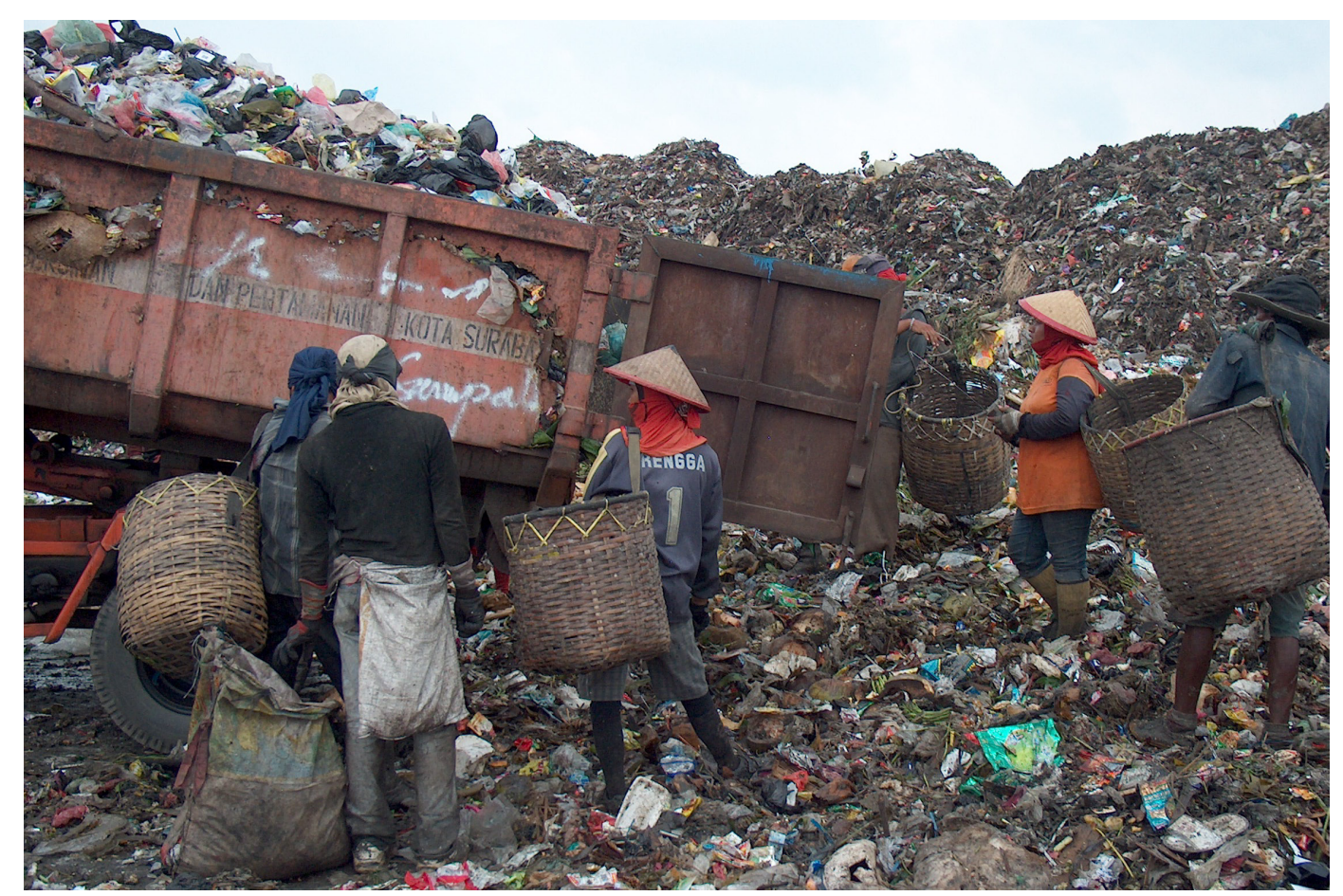

Catadores trabalhando em um depósito de lixo. Foto: Freek Colombijn 1996

\section{Conclusão}

As fábricas indonésias que produzem pellets a partir de plástico reciclado têm, deliberadamente, mantido um "low profile", como se diz em inglês, ou seja, têm se mantido discretas e em sigilo. A sua paradoxal invisibilidade é tornada possível por uma 
longa cadeia de fornecimento. O estigma negativo ligado ao plástico reciclado na Indonésia é direcionado para longe das fábricas e recai sobre os catadores e, em menor grau, sobre os negociantes de lixo e sucata e sobre os trituradores que sujam suas mãos com os resíduos a partir dos quais o plástico reciclado é selecionado. As fábricas distanciamse dos seus fornecedores: apenas um número limitado de varejistas e trituradores de sucata é autorizado a penetrar no portão da fábrica. $\mathrm{O}$ acesso seletivo às fábricas obriga os pequenos comerciantes a vender os seus fornecimentos a varejistas maiores, geralmente em várias etapas, e, consequentemente, a cadeia de fornecimento de materiais recicláveis cresce ainda mais, e a ligação entre a empresa que produz pellets e a fonte desses resíduos é cada vez mais obscura. Esta ofuscação de ligações entre os pontos extremos de uma cadeia de abastecimento é provavelmente verdadeira para todas as cadeias de abastecimento neoliberais, em todos os tipos de negócios.

Não só a distância da fonte permite que as fábricas se livrem da vergonha de trabalhar com resíduos, como também não precisam saber ("não podem saber") o que se passa anteriormente na cadeia de abastecimento. Não podem ser responsabilizadas por possíveis erros ambientais ou sociais, como a limpeza de plásticos sem o tratamento adequado de águas residuais, a reciclagem de plásticos médicos ou a atividade monótona e mal paga de pessoas que trabalham para comerciantes de lixo. Porém, as fábricas lucram com estes "erros", devido ao baixo preço dos plásticos reciclados.

Os diferentes intermediários no negócio da reciclagem formam uma rede extremamente complicada sobre a qual ninguém tem uma visão completa. $\mathrm{O}$ termo "rede de abastecimento" (supply network, em inglês, no original) seria mais apropriado do que o comumente utilizado, "cadeia de abastecimento" (supply chain, em inglês). As fábricas mantêm o controle sobre esta cadeia de abastecimento através do estabelecimento do padrão do material que aceitam e pelo seu poder de declarar que fornecedor é capaz e qual não o é. As fábricas são ajudadas no seu subterfúgio, pelo fato de não necessitarem negociar um preço determinado pela oferta e pela procura, porque o preço dos plásticos reciclados é fixado por um fator externo ao negócio da reciclagem: o preço internacional do petróleo.

Embora ninguém tenha uma visão completa de toda a cadeia de valor da reciclagem, os catadores de materiais recicláveis, os negociantes de lixo, os trituradores e as fábricas de pellets, o governo e os consumidores têm um hábito em comum: não querem saber exatamente o que se passa na reciclagem. Embora seja meio exagerado falar de 
uma conspiração de silêncio, a invisibilidade conspícua da indústria da reciclagem é certamente conveniente para todos a curto prazo.

No entanto, a longo prazo, uma maior abertura seria boa para todas as partes. $\mathrm{O}$ estatuto social dos catadores poderia ser melhorado, e o seu trabalho é o primeiro passo essencial na cadeia da reciclagem. As más condições de trabalho (especialmente daquelas pessoas que trabalham para os comerciantes de lixo) e as técnicas de produção poluentes (particularmente entre os trituradores que descarregam as águas residuais sem tratamento adequado) poderiam ser mais bem controladas, assim como as condições de trabalho e de produção nas fábricas que produzem pellets. A qualidade do plástico reciclado poderia ser mais bem garantida desde sua origem, até chegar ao produto final dos pellets, e a fraude seria evitada. Mais importante ainda, com melhor qualidade e com consumidores mais bem informados sobre o que se passa na reciclagem, os plásticos reciclados deixarão de ser uma alternativa barata, porém escondida, ao plástico virgem, podendo vir a tornar-se um produto amigo do meio ambiente, o que aumentaria a própria procura pelo plástico reciclado. Mesmo as fábricas que produzem pellets a partir de plástico reciclado lucrariam com tal abertura e transparência.

Tradução de Barbara Arisi ${ }^{5}$

5 Universidade Federal de Santa Catarina, Brasil. Email: barbara.arisi@gmail.com ORCID id: https://orcid.org/0000-0001-7560-9636 


\section{REFERÊNCIAS}

COLOMBIJN, Freek; MORBIDINI, Martina. Pros and Cons of the Formation of Waste-Pickers' Cooperatives: A Comparison between Brazil and Indonesia, Decision: Official Journal of Indian Institute of Management, Calcutta 44: 91-101. DOI: 10.1007/s40622-017-0149-5, 2017.

CRANG, Mike, et al. Rethinking Governance and Value in Commodity Chains through Global Recycling Networks, Transactions of the Institute of British Geographers 38: 12-24. DOI: 10.1111/j.1475-5661.2012.00515.x, 2013.

DOUGLAS, Mary. Purity and Danger: An Analysis of Concept of Pollution and Taboo. London and New York: Routledge [Routledge Classics, 2002], 1966.

GENOVESE, Andrea, et al. Sustainable Supply Chain Management and the Transition towards a Circular Economy: Evidence and some Applications, Omega 66: 344-357. DOI: 10.1016/j.omega.2015.05.015, 2017.

GEREFFI, Gary. The Global Economy: Organization, Governance, and Development. In: Neil J. Smelser \& Richard Swedberg (eds.) The Handbook of Economic Sociology. Princeton and Oxford: Princeton University Press and New York: Russell Sage Foundation. pp. 160-182, 2005.

GEREFFI, Gary; HUMPHREY, John; STURGEON, Timothy. The Governance of Global Value Chains, Review of International Political Economy 12: 78-104. DOI: 10.1080/09692290500049805, 2005.

GHISELLINE, Patrizia; CIALANI, Catia; ULGIATI, Sergio. A Review of Circular Economy: The Expected Transition to a Balanced Interplay of Environmental and Economic Systems, Journal of Cleaner Production 114: 11-32. DOI 10.1016/j.clepro.2015.09.007, 2016.

GREGSON, Nicky; CRANG, Mike. From Waste to Resource: The Trade in Wastes and Global Recycling Economies, Annual Review of Environmental Resources 40: 151-176. DOI: 10.1146/annurev-environ-102014-021105, 2015. 
JUDIANTI, Dwi Wahyuningtiyas. Studi Kelayakan Pemilahan dan Daur Ulang Sampah di Kecamatan Tandes Kota Surabaya. Unpublished master thesis Jurusan Teknik Linkungan, Institut Teknologi Surabaya Sepuluh Nopember, 2007.

KUMAR, Sameer; PUTNAM, Vaora. Cradle to Cradle: Reverse Logistics Strategies and Opportunities across Three Industry Sectors, International Journal of Production Economics 115: 305-315. DOI: 10.1016/j.ijpe.2007.11.015, 2008.

TSING, Anna. Supply Chains and the Human Condition, Rethinking Marxism 21: 148176. DOI: 10.1080/08935690902743088, 2009.

TSING, Anna Lowenhaupt. The Mushroom at the End of the World: On the Possibility of Life in Capitalist Ruins. Princeton and Oxford: Princeton University Press, 2015.

WORLD BANK. Indonesia Marine Debris Hotspot. [Jakarta:] World Bank Group, Kementerian Koordinator Bidang Kemaritiman, Embassy of Denmark and Royal Norwegian Embassy, 2018.

Agradecimentos:

Agradeço pelos comentários aos participantes do Workshop de Resíduos em Contexto, Universidade de Leiden, 6-7 de novembro de 2017. Gostaria de expressar também meu sincero agradecimento à antropóloga Bárbara M. Arisi pela tradução do artigo do Inglês ao português.

Recebido: 01/10/2020

Aprovado: $08 / 12 / 2020$ 